Article

\title{
Synthesis and Properties of Orthorhombic MoAlB Coatings
}

\author{
Jan-Ole Achenbach ${ }^{1, * \mathbb{C}}$, Rajib Sahu ${ }^{2}$, Bernhard Völker ${ }^{1,2}$, Marcus Hans ${ }^{1}{ }^{1}$, \\ Daniel Primetzhofer ${ }^{3}$, Danilo J. Miljanovic ${ }^{1}$, Christina Scheu ${ }^{1,2}$ and Jochen M. Schneider 1,2 \\ 1 Materials Chemistry, RWTH Aachen University, Kopernikusstr. 10, 52074 Aachen, Germany \\ 2 Max-Planck-Institut für Eisenforschung GmbH, Max-Planck-Str. 1, 40237 Düsseldorf, Germany \\ 3 Department of Physics and Astronomy, Uppsala University, Lägerhyddsvägen 1, 75120 Uppsala, Sweden \\ * Correspondence: achenbach@mch.rwth-aachen.de; Tel.: +49-241-80-25997
}

Received: 24 July 2019; Accepted: 9 August 2019; Published: 12 August 2019

\begin{abstract}
MoAlB is a potential candidate for high-temperature application since a dense, adherent alumina scale is formed. While, based on X-ray diffraction investigations, the formation of phase pure orthorhombic MoAlB coatings is observed, energy dispersive X-ray spectroscopy carried out in a scanning transmission electron microscope reveals the presence of Al-rich and O-rich regions within the MoAlB matrix. The oxidation kinetics of coatings and bulk is similar to the scale thickness formed on the MoAlB coating after oxidation at $1200^{\circ} \mathrm{C}$ for $30 \mathrm{~min}$ is similar to the one extrapolated for bulk MoAlB. Furthermore, the oxidation kinetics of MoAlB coatings is significantly lower than the one reported for bulk $\mathrm{Ti}_{2} \mathrm{AlC}$. Finally, the elastic properties measured for the as-deposited coatings are consistent ab initio predictions.
\end{abstract}

Keywords: MoAlB; coatings; physical vapor deposition (PVD); density functional theory (DFT); high-resolution transmission electron microscopy

\section{Introduction}

The synthesis of orthorhombic bulk MoAlB was reported by Rieger et al. in 1965 [1]. Kota et al. studied the oxidation behavior of bulk MoAlB produced by hot pressing from MoB and Al powders at $1200{ }^{\circ} \mathrm{C}$ for $5 \mathrm{~h} \mathrm{[2].} \mathrm{Xu} \mathrm{et} \mathrm{al.} \mathrm{studied} \mathrm{the} \mathrm{oxidation} \mathrm{behavior} \mathrm{of} \mathrm{bulk} \mathrm{MoAlB} \mathrm{synthesized} \mathrm{in} \mathrm{a} \mathrm{three-step}$ process of MoAlB powder synthesis at $1100{ }^{\circ} \mathrm{C}$, etching of surplus $\mathrm{Al}$, followed by hot pressing at $1600{ }^{\circ} \mathrm{C}$ to increase the density. It was shown that a dense, protective, and adherend alumina scale is formed on bulk MoAlB after cyclic oxidation at $1600{ }^{\circ} \mathrm{C}$ for a total of $50 \mathrm{~h}$ [3]. Shi et al. oxidized needle-shaped and plate-like MoAlB single crystals and inferred from the difference in average weight loss that the oxidation behavior is anisotropic [4]. While the application at high temperatures of most transition metal borides is hampered by their limited oxidation resistance above $1200^{\circ} \mathrm{C}[5,6], \mathrm{MoAlB}$ forms a protective $\mathrm{Al}_{2} \mathrm{O}_{3}$ layer [2], and was reported to be capable of self-healing [7] and hence, holds great promise as a high-temperature material $[2,3,7,8]$.

Here, we report the synthesis of orthorhombic MoAlB coatings for the first time and compare the oxidation behavior at $1200{ }^{\circ} \mathrm{C}$ to literature reports for bulk material $[7,8]$ and $\mathrm{Ti}_{2} \mathrm{AlC}[9,10]$.

\section{Materials and Methods}

\subsection{Experimental Methods}

MoAlB coatings were synthesized by combinatorial DC magnetron sputtering [11] using a two target setup. The depositions were carried out in a lab-scale sputtering system [12]. A compound MoB (2" diameter, Plansee Composite Materials GmbH, Lechbruck am See, Germany) and an elemental Al 
(2" diameter, $99.99 \%$ purity) target were placed each at a $45^{\circ}$ angle with respect to the substrate normal. This geometric arrangement enables the deposition of Mo-Al-B coatings with an Al concentration gradient, commonly referred to as composition spread. The target-to-substrate distance was $10 \mathrm{~cm}$. One side-polished $\mathrm{Al}_{2} \mathrm{O}_{3}$ (0001) single crystal wafers with a diameter of 2" were used as substrates. Prior to deposition onto the polished substrate surface, the unpolished sapphire wafer side was covered with approximately $300 \mathrm{~nm}$ of Mo to enable efficient heat absorption from the heater positioned behind the substrate. The magnetrons were powered by MDX $2.5 \mathrm{~kW}$ (Advanced Energy, Fort Collins, CO, USA) and Maris GS 15 (ADL, Darmstadt, Germany) generators, supplying power densities of 6.1 and $1.5 \mathrm{~W} / \mathrm{cm}^{2}$ to the $\mathrm{MoB}$ and $\mathrm{Al}$ targets, respectively. The base pressure at the deposition temperature of $700{ }^{\circ} \mathrm{C}$ was $<1.1 \times 10^{-4} \mathrm{~Pa}$. Sputtering was conducted at an $\mathrm{Ar}(99.999 \%$ purity) pressure of $0.35 \mathrm{~Pa}$. The deposition time was $2 \mathrm{~h}$, and the coating thickness for the close to stoichiometric composition was $1.86 \pm 0.05 \mu \mathrm{m}$. Hence, the deposition rate for the close to stoichiometric composition was $0.93 \mu \mathrm{m} / \mathrm{h}$.

Phase formation was investigated with a Bruker D8 Discovery general area detector diffraction system (GADDS) (Bruker, Billerica, MA, USA) using $\mathrm{Cu}(\mathrm{K} \alpha)$ radiation with a grazing incident angle of $10^{\circ}$.

Nanoindentation was performed with a Hysitron TI-950 TriboIndenter ${ }^{\mathrm{TM}}$ (Bruker, Eden Prairie, MN, USA). Young's modulus and hardness values were obtained by the method of Oliver and Pharr [13]. Load-controlled measurements were carried out with a maximum load of $10 \mathrm{mN}$, resulting in an average contact depth of $157 \mathrm{~nm}(<10 \%$ of coating thickness). A diamond Berkovich tip ( $100 \mathrm{~nm}$ radius) was used, and 100 load-displacement data sets were utilized to calculate the average elastic modulus from the indentation modulus utilizing the Poisson's ratio of $v=0.23$ which was obtained by ab initio calculations.

The chemical composition of the combinatorial coating was measured by energy dispersive X-ray spectroscopy (EDX) attached to a JEOL JSM-6480 scanning electron microscope (SEM) (JEOL Ltd., Tokyo, Japan) operated at an acceleration voltage of $5 \mathrm{kV}$. A calibration sample for EDX was quantified by time-of-flight elastic recoil detection analysis (ToF-ERDA), details can be found in the work of Gleich et al. [14]. The coating with close to stoichiometric composition (Figure 1b) was measured 6 times to determine the statistical uncertainty of EDX to be $4 \%$ relative. The statistical uncertainty of the ERDA analysis was $<0.5 \%$ absolute. Due to the uncertainty of the specific energy loss of the probing ions and the constituents and of the target, a systematic uncertainty of $5 \%$ to $10 \%$ relative of the values for the deduced concentrations was assumed. Thus, the concentrations obtained from ERDA-calibrated EDX measurements were calculated to be subject to cumulative measurement uncertainties between $6 \%$ and $11 \%$ relative deviation.

Thin lamellae ( $<100 \mathrm{~nm}$ thickness) of the MoAlB coatings in the as-deposited state as well as after oxidation for $30 \mathrm{~min}$ at $1200^{\circ} \mathrm{C}$ in ambient air were prepared by focused ion beam (FIB) utilizing an FEI Helios Nanolab 660 dual-beam microscope(Thermo Fisher Scientific, Waltham, MA, USA). Subsequently, the cross-section morphology was investigated utilizing a JEOL JSM-2100 transmission electron microscope (TEM) in scanning mode (STEM) with an acceleration voltage of $200 \mathrm{kV}$. In addition, a lamella from the MoAlB coating with close to stoichiometric composition was analyzed in detail by several TEM methods, such as high resolution TEM (HRTEM), high-angle annular dark field (HAADF) imaging in STEM, selected area electron diffraction (SAED), EDX, and electron energy loss spectroscopy (EELS). The HRTEM was performed using an FEI spherical aberration (Cs) image corrected Titan Themis at an acceleration voltage of $300 \mathrm{kV}$. Both STEM-EELS and STEM-EDX mapping were conducted with an FEI Titan Themis equipped with Cs probe corrector and high-energy resolution Gatan image filter (Quantum) operating at $300 \mathrm{keV}$ acceleration voltage. Compositional area fractions were quantified from EDX spectra utilizing the MATLAB code presented in the work of Zhan et al. [15]. Core loss STEM-EELS spectra were acquired at $1 \mathrm{eV}$ energy resolution measured from the full width of half maxima of the zero-loss peak. The spectra were collected with a $5 \mathrm{~nm}$ aperture at an energy dispersion of $0.10 \mathrm{eV}$ per Channel. 


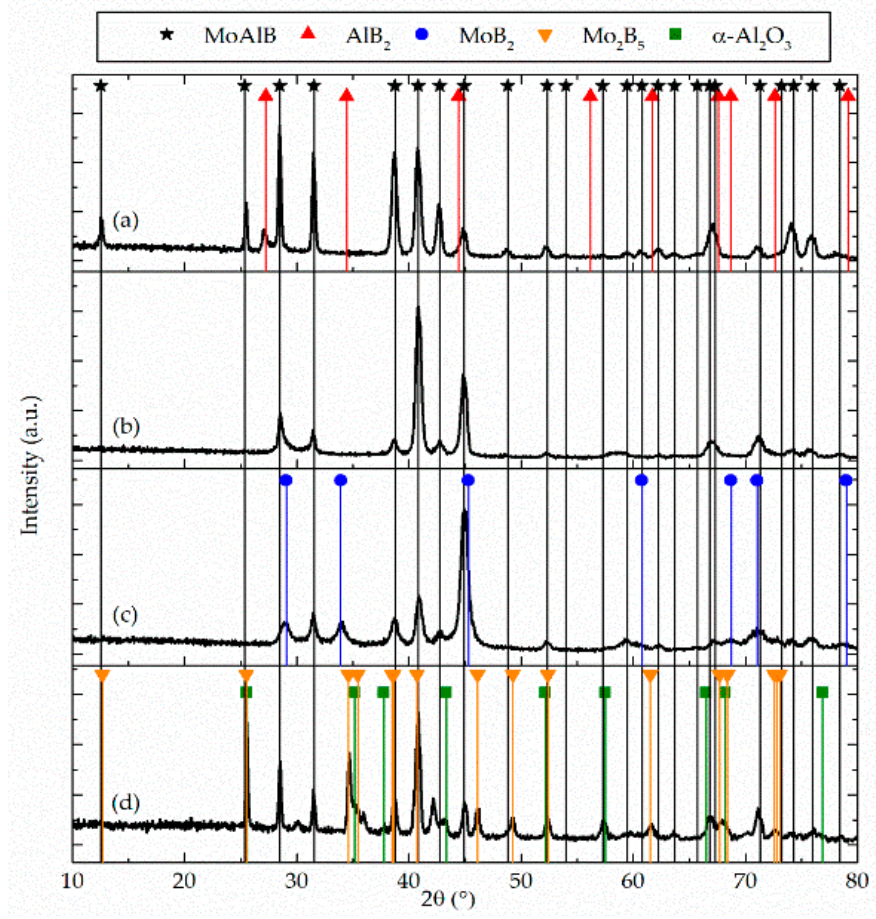

Figure 1. X-ray diffraction data of Al-rich $\operatorname{MoAlB}(\mathbf{a})$, close to stoichiometric MoAlB (b), and Al-deficient MoAlB (c) deposited at $700{ }^{\circ} \mathrm{C}$ substrate temperature. Close to stoichiometric MoAlB annealed at 1200 ${ }^{\circ} \mathrm{C}$ for $30 \mathrm{~min}$ in ambient air is shown in (d). For all compositions, the orthorhombic MoAlB crystal structure is the dominant phase.

\subsection{Theoretical Methods}

Density functional theory (DFT) [16] calculations implemented within the Vienna ab initio simulation package (VASP) $[17,18]$ were performed to calculate the elastic moduli of MoAlB. Generalized gradient approximation (GGA) parametrized by Perdew, Burke, and Ernzerhof (PBE) [19] was used with projector augmented wave potentials [20]. Reciprocal space integration using the Monkhorst-Pack scheme [21] as well as the tetrahedron method for total energy using Blöchl-corrections [22] were employed for the calculations. The used $k$-point grid was $8 \times 8 \times 8$ for a unit cell containing a total of 12 atoms. Electronic relaxation convergence and energy cut-offs were $0.01 \mathrm{meV}$ and $500 \mathrm{eV}$, respectively. For the determination of elastic constants, the formalism described by Ravindran et al. [23] was used. Approximations of Reuss [24], Voigt [25], and Hill [26] were applied to estimate the shear modulus G and bulk modulus $B$. The Young's modulus $E$ is calculated from Equation (1).

$$
E=\frac{9 B G}{3 B+G}
$$

\section{Results and Discussion}

Structural and compositional data obtained along the $\mathrm{Al}$ concentration gradient of the composition spread in the MoAlB coating are presented in Figure 1 and Table 1, respectively. The diffraction data (Figure 1a) determined for the Al-rich coating with $\mathrm{Mo} / \mathrm{Al}=0.73$ and $\mathrm{Mo} / \mathrm{B}=1.04$ was consistent with a phase mixture of orthorhombic MoAlB and hexagonal $\mathrm{AlB}_{2}$. All diffraction data determined for the coating with close to the stoichiometric composition of $\mathrm{Mo} / \mathrm{Al}=0.93$ and $\mathrm{Mo} / \mathrm{B}=0.87$ provide evidence for the formation of phase pure orthorhombic MoAlB (Figure 1b). The diffraction data for the Al-deficient coatings with $\mathrm{Mo} / \mathrm{Al}=1.38$ and $\mathrm{Mo} / \mathrm{B}=0.83$ can be attributed to the formation of hexagonal $\alpha-\mathrm{MoB}_{2}$ in addition to the MoAlB phase (Figure 1c). It may be speculated that the changes in preferred orientation observed along the $\mathrm{Al}$ concentration gradient were at least, in part, caused by changes in chemical composition as well as by the formation of secondary phases. Annealing the 
close to stoichiometric MoAlB coating at $1200{ }^{\circ} \mathrm{C}$ for $30 \mathrm{~min}$ in ambient air resulted in the formation of $\alpha-\mathrm{Al}_{2} \mathrm{O}_{3}$ and rhombohedral $\mathrm{Mo}_{2} \mathrm{~B}_{5}$ phases (Figure 1d). The Al-rich coating is the only one where the MoAlB basal plane peak (020) at $12.7^{\circ}$ can be identified. In all other coatings the basal plane peak intensity is very low. The oxygen content of all as-deposited samples is $\leq 6$ at. $\%$ and may originate from impurities within the target, residual gases in the process chamber [27] and subsequent oxidation due to atmosphere exposure [28].

Table 1. Compositional data of as-deposited coatings.

\begin{tabular}{ccccc}
\hline Coating & Mo (at.\%) & Al (at.\%) & B (at.\%) & O (at.\%) \\
\hline Al-rich & $28.9 \pm 3.2$ & $39.4 \pm 4.3$ & $28 \pm 3$ & $4 \pm 1$ \\
close to & $29.4 \pm 3.2$ & $31.5 \pm 3.5$ & $34 \pm 4$ & $5 \pm 1$ \\
stoichiometric & $32.0 \pm 3.5$ & $23.2 \pm 2.6$ & $39 \pm 4$ & $6 \pm 1$ \\
Al-deficient & &
\end{tabular}

The MoAlB coating synthesis temperature of $700{ }^{\circ} \mathrm{C}$ reported here, is $500{ }^{\circ} \mathrm{C}$ lower as the temperature utilized during reactive hot pressing of bulk MoAlB [15]. It is reasonable to assume that the significant decrease in synthesis temperature is enabled by surface diffusion during vapor-phase condensation similarly to $\mathrm{Mo}_{2} \mathrm{BC}$ [29] and $\mathrm{Cr}_{2} \mathrm{AlC}$ [30].

HRTEM images of the close to stoichiometric coatings in Figure 2a provide interplanar spacing indicating the formation of MoAlB. No evidence for the formation of impurity phases was obtained. Two different grains were examined along [1] (Figure 2a,b) and [10] (Figure 2c). The lattice spacing of the (020) plane was $6.98 \AA$, corresponding to a $b$ lattice vector of $13.96 \pm 0.26 \AA$ (see Table 2). From Figure $2 \mathrm{c}$ we deduced lattice parameters of $a=3.17 \pm 0.16 \AA$ and $c=3.12 \pm 0.08 \AA$. The uncertainties were based on the standard deviation of 20 measurements. Both, the theoretically and the experimentally determined lattice parameters deviate by $<1.6 \%$ with respect to each other and to previous reports (see Table 2). Considering the employed exchange-correlation functionals within DFT, a relative error of $\leq 2 \%$ has to be expected for lattice constants [31]. Hence, the here reported theoretical and experimental data are in excellent agreement with each other as well as with previous reports $[2,32]$.
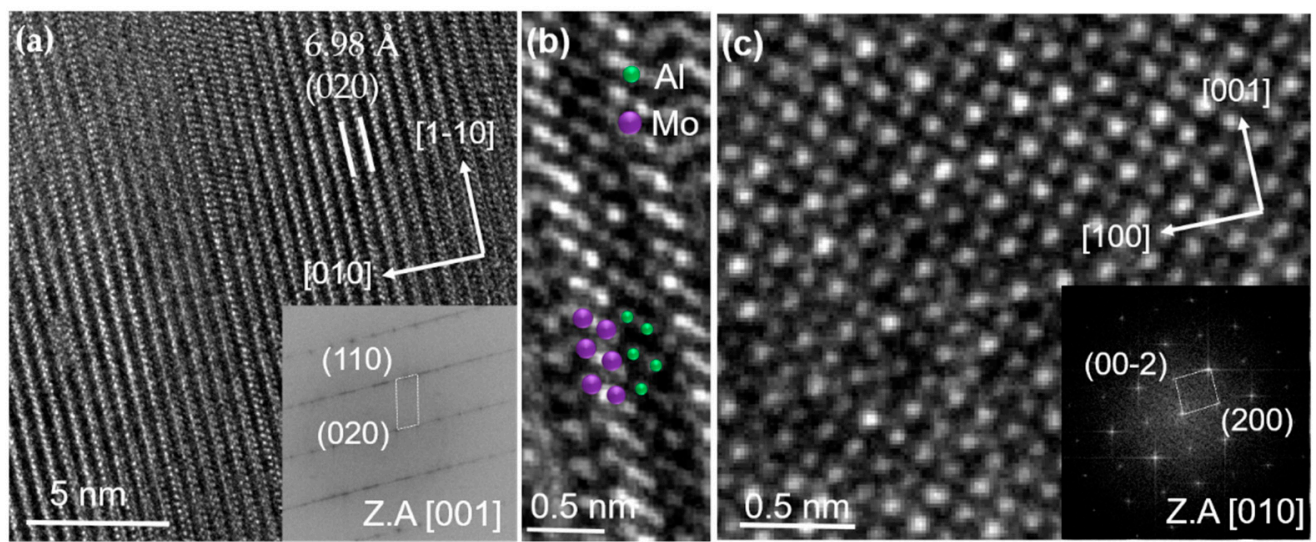

Figure 2. HRTEM images of the close to stoichiometric coatings from (a) and (b) show the atomic arrangement of Mo and Al along [1] zone axis and (c) along [10] zone axis. Purple and green symbols represent positions of $\mathrm{Mo}$ and $\mathrm{Al}$ in Figure $2 \mathrm{~b}$. The insets present the corresponding fast Fourier transform (FFT). 
Table 2. Experimental and theoretical lattice parameters of MoAlB compared to literature data.

\begin{tabular}{cccc}
\hline $\boldsymbol{a}(\AA)$ & $\boldsymbol{b}(\AA)$ & $\boldsymbol{c}(\AA)$ & Ref. \\
\hline $3.24 \pm 0.04$ & $13.95 \pm 0.72$ & $3.10 \pm 0.08$ & XRD \\
$3.17 \pm 0.16$ & $13.96 \pm 0.26$ & $3.12 \pm 0.08$ & HRTEM/SAED \\
3.223 & 14.016 & 3.110 & DFT \\
3.21 & 13.98 & 3.10 & {$[2]$} \\
3.2227 & 14.037 & 3.1067 & {$[32]$} \\
\hline
\end{tabular}

STEM-EDX (Figure 3b,d)) and STEM-EELS (Figure 3f) measurements were performed to qualitatively analyze the local elemental composition of the MoAlB coating with a close to stoichiometric integral composition. Darker regions in the HAADF STEM image depicting the as-deposited state may be caused by the local enrichment of light elements, such as oxygen, and/or by the presence of pores. The EELS data, averaged over the identical region as mapped by EDX, show the element-specific Al $\mathrm{L}_{2,3}(73.5 \mathrm{eV}), \mathrm{Al} \mathrm{L}_{1}(119.4 \mathrm{eV})$, and B K $(192.2 \mathrm{eV})$ edges. The observed reflections in the SAED pattern (Figure 3e) confirm the formation of orthorhombic MoAlB consistent with XRD. However, additional reflections, indicated by black arrows, are attributed to a yet unidentified impurity phase. Principle component analysis (PCA) of the EDX map using the code described in [15] revealed the presence of two impurity phases besides the main MoAlB phase: An Al-rich and O-rich phase. The obtained weight maps for $\mathrm{Al}$ and $\mathrm{O}$ are displayed in Figure 4. The maps were subsequently used to calculate the areal fraction of the Al-rich and O-rich impurity phases and found to be on the order of $4 \%$ and $5 \%$ to $6 \%$, respectively.
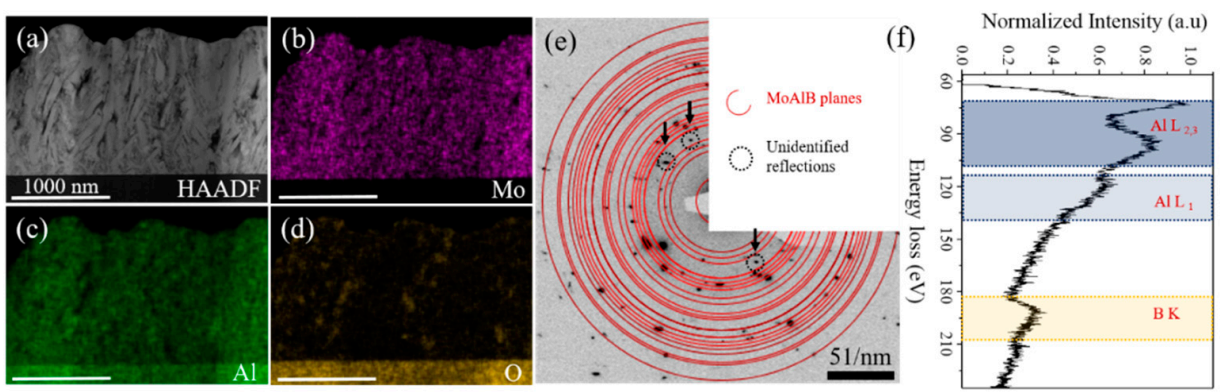

Figure 3. HAADF STEM image of a cross-section obtained from the close-to-stoichiometric coating (a); (b-d) show STEM-EDX maps for $\mathrm{Mo}, \mathrm{Al}$, and $\mathrm{O}$, respectively; reflections in SAED pattern (e) indicate the formation of orthorhombic MoAlB. Unidentified reflections are marked with black arrows; (f) shows the EELS data in the energy loss region of the $\mathrm{Al} \mathrm{L}$, and $\mathrm{B}$ K edges.
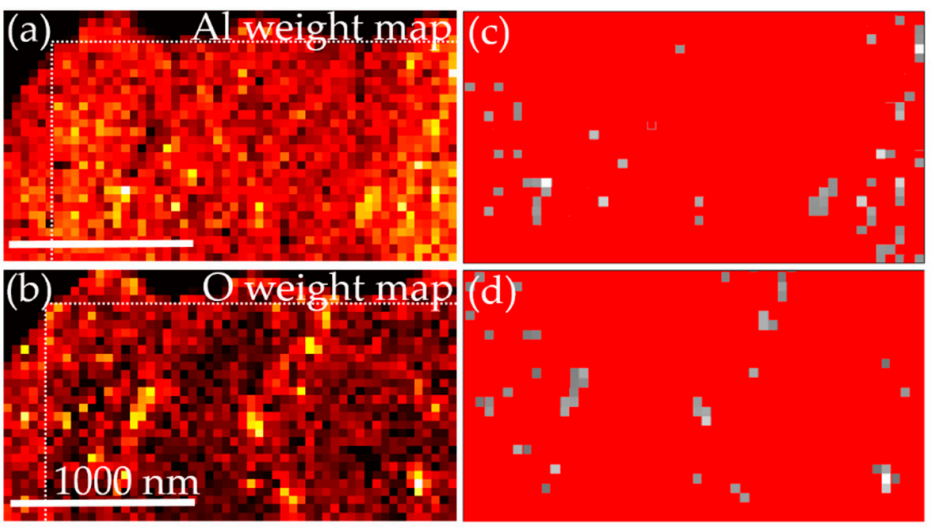

Figure 4. (a) and (b) depict the EDX weight mappings processed with the MATLAB Code from Zhang et al. [15] for $\mathrm{Al} \mathrm{(a)} \mathrm{and} \mathrm{O}(\mathbf{b})$. Area fraction (grey regions) of Al-rich (c) and O-rich (d) impurity phases analyzed utilizing ImageJ. The areal fraction for the Al-rich and O-rich phase is $4 \%$ and $5 \%$ to $6 \%$, respectively. 
STEM cross-sectional images of the close-to-stoichiometric MoAlB coating before and after oxidation are shown in Figure 5. In the as-deposited state, the coating thickness is $1.86 \pm 0.05 \mu \mathrm{m}$ compared to a total coating thickness after annealing of $2.19 \pm 0.14 \mu \mathrm{m}$ consisting of coating and oxide scale. Pores with a diameter of up to $500 \mathrm{~nm}$ form in the oxidized coating. Pore formation during oxidation of bulk MoAlB was previously observed by Kota et al. [8] and Lu et al. [7] and was attributed to the evaporation of volatile $\mathrm{MoO}_{3}$ and $\mathrm{B}_{2} \mathrm{O}_{3}$ [7]. Oxide scale growth of $0.59 \pm 0.12 \mu \mathrm{m}$ in $30 \mathrm{~min}$ was observed for the MoAlB coating annealed at $1200^{\circ}$ for $30 \mathrm{~min}$ (Figure $4 \mathrm{~b}, \mathrm{c}$ ). According to Kota et al., the mass gain oxidation kinetics of bulk MoAlB at $1200{ }^{\circ} \mathrm{C}$ is closer to linear than to parabolic or cubic [8]. However, if the scale thickness is considered, the best fits to the measured data are given by cubic and parabolic kinetics with correlation coefficients of 0.972 and 0.967 , respectively. For bulk MoAlB, a scale thickness at identical oxidation conditions of $1.42 \pm 0.57 \mu \mathrm{m}$ and $0.52 \pm 0.21 \mu \mathrm{m}$ can be calculated using the rate constants reported by Kota et al. [8] of $1.60 \times 10^{-21} \mathrm{~m}^{3} \mathrm{~s}^{-1}$ and $1.49 \times 10^{-16} \mathrm{~m}^{2} \mathrm{~s}^{-1}$ for cubic and parabolic kinetics, respectively. It has to be kept in mind that these thickness values are computed from kinetics data for which the shortest oxidation time was $5 \mathrm{~h}$. The thickness error given above was estimated assuming the same relative uncertainty than reported for the $5 \mathrm{~h}$ oxidation data, namely $\pm 40 \%$. Recently, Lu et al. [7] investigated the oxidation of bulk MoAlB at $1200{ }^{\circ} \mathrm{C}$ for up to $10 \mathrm{~h}$ and reported thickness measurements of the oxide scale in $2 \mathrm{~h}$ intervals. They reported parabolic scale thickening kinetics. In addition, from these investigations, we have extrapolated the scale thickness to be expected at $30 \mathrm{~min}$ oxidation time and obtained $0.6 \pm 0.05 \mu \mathrm{m}$ which is in excellent agreement with the here measured scale thickness formed on the MoAlB coating, see Figure 6. As no rate constant was reported by Lu et al., the data reported in Figure 1 of reference [5] was utilized for the aforementioned extrapolation. Similarly to the extrapolation discussed above also here, it has to be kept in mind that the thickness value was extrapolated from thickness data for which the shortest oxidation time was $2 \mathrm{~h}$ and that the thickness error given is estimated assuming the same relative uncertainty than reported for the $2 \mathrm{~h}$ oxidation namely $\pm 8 \%$. In Figure 6 the here measured data are compared with extrapolated literature data of the oxide scale growth of bulk MoAlB [7,8], and it is evident that the MoAlB coating (black) exhibits similar oxidation behavior as bulk MoAlB.

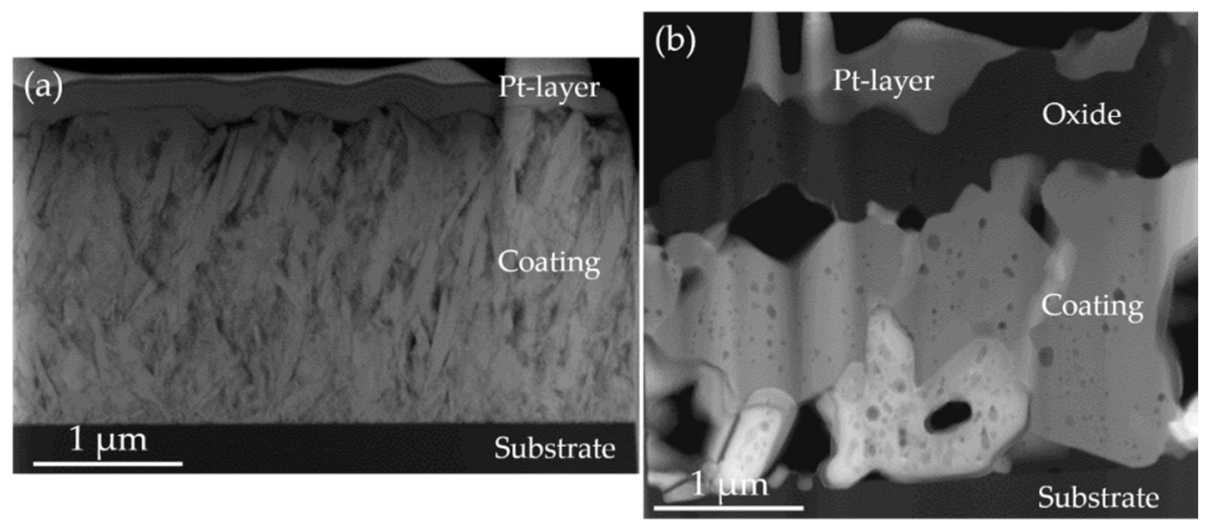

Figure 5. STEM of close-to-stoichiometric MoAlB coating: (a) as-deposited, (b) after oxidation in ambient air for $1200{ }^{\circ} \mathrm{C}$. The top layer corresponds to the Pt protection layer, which is deposited during the FIB sample preparation. 


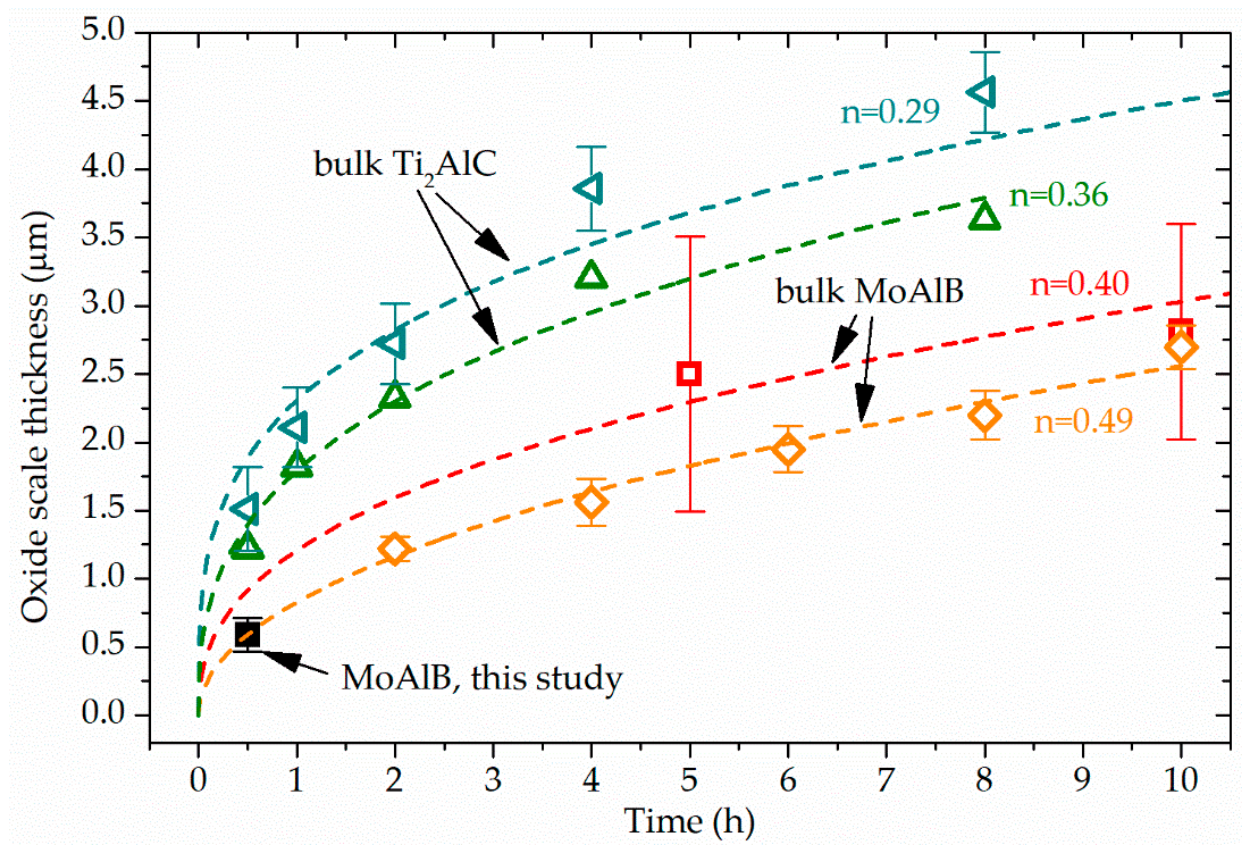

Figure 6. Comparison of oxide scale thickness formed at $1200{ }^{\circ} \mathrm{C}$ in air of the here investigated MoAlB coating with bulk MoAlB and bulk $\mathrm{Ti}_{2} \mathrm{AlC}$. The bulk $\mathrm{Ti}_{2} \mathrm{AlC}$ data are plotted in dark teal left-hand triangle [9] and green triangle [10] while the bulk MoAlB data are plotted in red square [8] and orange inclined square [7]. For the oxidation behavior of bulk MoAlB, the reported power factors of $n=0.40$ [8] and $n=0.49$ [7] were utilized to compute the dashed lines for red square and orange inclined square, respectively. For the $\mathrm{Ti}_{2} \mathrm{AlC}$ data reported in references [9] and [10], the power factors were calculated according to Equation (2). The calculated power factors $\mathrm{n}$ are given.

As the similarity notion above is based on extrapolation rather than on direct comparison with oxide thickness data, the oxidation behavior of the MoAlB coating was also compared to that of alumina forming bulk $\mathrm{Ti}_{2} \mathrm{AlC}[9,10]$. This comparison is shown in Figure 6. The power factor $n$ for the $\mathrm{Ti}_{2} \mathrm{AlC}$ data from references [9] and [32] were calculated with Equation (2), where $\mathrm{d}$ is the oxide scale thickness, $K$ the rate law constant, and $t$ the oxidation time.

$$
d=K t^{n}
$$

The reported oxide scale thickness formed on bulk $\mathrm{Ti}_{2} \mathrm{AlC}$ when oxidized in dry air at $1200{ }^{\circ} \mathrm{C}$ for $30 \mathrm{~min}$ were $1.50 \pm 0.30 \mu \mathrm{m}$ [9] and $1.22 \pm 0.05 \mu \mathrm{m}$ [10] and are hence, at least twice as large as the here reported scale thickness on the MoAlB coating at identical oxidation temperature and duration. After $8 \mathrm{~h}$ at $1200{ }^{\circ} \mathrm{C}$, the reported scale thicknesses on bulk $\mathrm{Ti}_{2} \mathrm{AlC}$ were with $3.63 \pm 0.08 \mu \mathrm{m}[10]$ and $4.56 \pm 0.29 \mu \mathrm{m}$ [9] also significantly larger as the reported bulk MoAlB scale thickness of $2.20 \pm 0.18 \mu \mathrm{m}[7]$.

Hence, as the here reported MoAlB coating exhibited less than half of the oxide scale thickness as bulk $\mathrm{Ti}_{2} \mathrm{AlC}$ after $30 \mathrm{~min}$ oxidation at $1200^{\circ} \mathrm{C}$. This mirrored the oxidation behavior comparison between bulk MoAlB [7] and bulk $\mathrm{Ti}_{2} \mathrm{AlC}[9,10]$, where significantly larger oxide scale thicknesses were observed for $\mathrm{Ti}_{2} \mathrm{AlC}$, see Figure 6 .

The theoretically determined Young's modulus of 359 GPa was well within the error margin of Young's modulus determined by nanoindentation of $349 \pm 57 \mathrm{GPa}$. The scattering of experimental data of $\pm 16 \%$ is most likely caused by the surface roughness of $R_{\mathrm{a}}=44 \mathrm{~nm}$ determined by laser optical microscopy. The relative error of elastic properties determined by DFT of $\leq 20 \%$ for the employed exchange-correlation functionals has to be expected [31]. Theoretically predicted and experimentally determined moduli of $G_{D F T}=145 \mathrm{GPa}, E_{D F T}=359 \mathrm{GPa}, B_{\mathrm{DFT}}=225 \mathrm{GPa}$, and $E_{\exp }$ $=349 \pm 57 \mathrm{GPa}$ from this work deviated by $<7 \%$ compared with moduli determined by resonant 
ultrasound spectroscopy of $G=151.2 \mathrm{GPa}, E=372.9 \mathrm{GPa}$, and $B=232.9 \mathrm{GPa}$ at $300 \mathrm{~K}$ [33], and hence, are in excellent agreement. The determined hardness value of $13 \pm 3 \mathrm{GPa}$ was comparable to reported hardness values of $10.3 \pm 0.2 \mathrm{GPa}$ [2] and 11.4 to 13.6 GPa [34] determined for bulk MoAlB and single-crystal MoAlB, respectively. It is reasonable to assume that this hardness increase may be caused by orders of magnitude smaller grain sizes in coatings (typically $<100 \mathrm{~nm}$ ) compared to bulk materials (typically $>1 \mu \mathrm{m}$ ). The calculated $B / G$ ratio [35] and Cauchy pressure [36] of MoAlB predicted brittle behavior and were comparable to hard coatings, such as TiN and TiAlN, as shown in Table 3.

Table 3. B/G ratio, Cauchy pressures for (100), (010), and (001) planes.

\begin{tabular}{cccccc}
\hline Material & $\frac{B}{G}$ & $C_{23}-C_{44}(\mathrm{GPa})$ & $C_{13}-C_{55}(\mathrm{GPa})$ & $C_{12}-C_{66}(\mathrm{GPa})$ & Reference \\
\hline MoAlB & 1.55 & -61 & 10 & -20 & This study \\
$\mathrm{Mo}_{2} \mathrm{BC}$ & 1.73 & 27 & -31 & 31 & {$[37]$} \\
$\mathrm{TiN}$ & 1.58 & -21 & -21 & -21 & {$[38]$} \\
VAlN & 1.40 & - & - & - & {$[39]$} \\
TiAlN & 1.42 & -45 & -45 & -45 & {$[40]$} \\
\hline
\end{tabular}

\section{Conclusions}

In this work X-ray phase pure, orthorhombic MoAlB coatings were grown at $700{ }^{\circ} \mathrm{C}$. High-resolution transmission electron microscopy reveals an interplanar spacing which is in excellent agreement with the lattice parameter determined by $\mathrm{X}$-ray diffraction and ab initio predictions as well as literature reports. In selected area electron diffraction and compositional area fraction analysis, additional, yet unidentified, Al-rich and O-rich minority phases were observed. MoAlB coatings exhibit similar oxidation behavior as bulk MoAlB as the oxide scale thickness formed on MoAlB coatings after oxidation at $1200{ }^{\circ} \mathrm{C}$ for $30 \mathrm{~min}$ was similar to the one extrapolated for bulk MoAlB. Furthermore, MoAlB coatings exhibited significantly lower oxidation kinetics than bulk $\mathrm{Ti}_{2} \mathrm{AlC}$. Measured elastic properties of the as-deposited MoAlB coatings were in excellent agreement with ab initio predictions and literature values for bulk MoAlB. The calculated $B / G$ ratio and Cauchy pressure were comparable to hard coatings, such as TiN and TiAlN.

Author Contributions: Conceptualization, J.O.A. and J.M.S.; Data curation, J.O.A. and R.S.; Investigation, J.O.A., R.S., B.V., M.H., D.P., D.J.M., and C.S.; Methodology, J.O.A., R.S., B.V., M.H., D.P., D.J.M., and C.S.; Writing-original draft, J.O.A. and J.M.S.; Writing—review and editing, R.S., B.V., M.H., D.P., D.J.M., and C.S.

Funding: This research received no external funding.

Acknowledgments: J.M.S. gratefully acknowledges financial support from the MPG fellow program. Simulations were performed with computing resources granted by JARAHPC from the RWTH Aachen University under Project No. JARA0131. Financial support for the operation of the accelerator laboratory in Uppsala by VR-RFI (contract 821-2012-5144) and the Swedish Foundation for Strategic Research (SSF, contract RIF14-0053) is gratefully acknowledged by D.P.

Conflicts of Interest: The authors declare no conflict of interest.

\section{References}

1. Rieger, W.; Nowotny, H.; Benesovsky, F. Über einige Komplexboride von Übergangsmetallen. Monatshefte für Chemie und verwandte Teile anderer Wissenschaften 1965, 96, 844-851. [CrossRef]

2. Kota, S.; Zapata-Solvas, E.; Ly, A.; Lu, J.; Elkassabany, O.; Huon, A.; Lee, W.E.; Hultman, L.; May, S.J.; Barsoum, M.W. Synthesis and characterization of an alumina forming nanolaminated boride: MoAlB. Sci. Rep. 2016, 6, 26475. [CrossRef] [PubMed]

3. Xu, L.; Shi, O.; Liu, C.; Zhu, D.; Grasso, S.; Hu, C. Synthesis, microstructure and properties of MoAlB ceramics. Ceram. Int. 2018, 44, 13396-13401. [CrossRef]

4. Shi, O.; Xu, L.; Jiang, A.; Xu, Q.; Xiao, Y.; Zhu, D.; Grasso, S.; Hu, C. Synthesis and oxidation resistance of MoAlB single crystals. Ceram. Int. 2019, 45, 2446-2450. [CrossRef] 
5. Parthasarathy, T.; Rapp, R.; Opeka, M.; Kerans, R. A model for the oxidation of $\mathrm{ZrB}_{2}, \mathrm{HfB}_{2}$ and TiB 2 . Acta Mater. 2007, 55, 5999-6010. [CrossRef]

6. Fahrenholtz, W.; Hilmas, G. Oxidation of ultra-high temperature transition metal diboride ceramics. Int. Mater. Rev. 2012, 57, 61-72. [CrossRef]

7. Lu, X.; Li, S.; Zhang, W.; Yao, B.; Yu, W.; Zhou, Y. Crack healing behavior of a MAB phase: MoAlB. J. Eur. Ceram. Soc. 2019. [CrossRef]

8. Kota, S.; Zapata-Solvas, E.; Chen, Y.; Radovic, M.; Lee, W.E.; Barsoum, M.W. Isothermal and Cyclic Oxidation of MoAlB in Air from $1100{ }^{\circ} \mathrm{C}$ to $1400{ }^{\circ} \mathrm{C}$. J. Electrochem. Soc. 2017, 164, C930-C938. [CrossRef]

9. Song, G.; Schnabel, V.; Kwakernaak, C.; Van der Zwaag, S.; Schneider, J.; Sloof, W. High temperature oxidation behaviour of $\mathrm{Ti}_{2} \mathrm{AlC}$ ceramic at $1200{ }^{\circ} \mathrm{C}$. Mater. High Temp. 2012, 29, 205-209. [CrossRef]

10. Li, S.; Song, G.; Kwakernaak, K.; van der Zwaag, S.; Sloof, W.G. Multiple crack healing of a Ti ${ }_{2} \mathrm{AlC}_{\mathrm{C}}$ ceramic. J. Eur. Ceram. Soc. 2012, 32, 1813-1820. [CrossRef]

11. Gebhardt, T.; Music, D.; Takahashi, T.; Schneider, J.M. Combinatorial thin film materials science: From alloy discovery and optimization to alloy design. Thin Solid Film. 2012, 520, 5491-5499. [CrossRef]

12. Herrig, F.; Music, D.; Völker, B.; Hans, M.; Pöllmann, P.J.; Ravensburg, A.L.; Schneider, J.M. Ab Initio Guided Low Temperature Synthesis Strategy for Smooth Face-Centred Cubic FeMn Thin Films. Metals 2018, 8, 384. [CrossRef]

13. Oliver, W.C.; Pharr, G.M. An improved technique for determining hardness and elastic modulus using load and displacement sensing indentation experiments. J. Mater. Res. 1992, 7, 1564-1583. [CrossRef]

14. Gleich, S.; Soler, R.; Fager, H.; Bolvardi, H.; Achenbach, J.-O.; Hans, M.; Primetzhofer, D.; Schneider, J.M.; Dehm, G.; Scheu, C. Modifying the nanostructure and the mechanical properties of Mo2BC hard coatings: Influence of substrate temperature during magnetron sputtering. Mater. Des. 2018, 142, 203-211. [CrossRef]

15. Zhang, S.; Scheu, C. Evaluation of EELS spectrum imaging data by spectral components and factors from multivariate analysis. Microscopy 2017, 67, i133-i141. [CrossRef] [PubMed]

16. Hohenberg, P.; Kohn, W. Inhomogeneous electron gas. Phys. Rev. 1964, 136, B864. [CrossRef]

17. Kresse, G.; Hafner, J. Ab initio molecular dynamics for open-shell transition metals. Phys. Rev. B 1993, 48, 13115. [CrossRef] [PubMed]

18. Kresse, G.; Hafner, J. Ab initio molecular-dynamics simulation of the liquid-metal-amorphous-semiconductor transition in germanium. Phys. Rev. B 1994, 49, 14251. [CrossRef] [PubMed]

19. Perdew, J.P.; Burke, K.; Ernzerhof, M. Generalized gradient approximation made simple. Phys. Rev. Lett. 1996, 77, 3865. [CrossRef]

20. Kresse, G.; Joubert, D. From ultrasoft pseudopotentials to the projector augmented-wave method. Phys. Rev. B 1999, 59, 1758. [CrossRef]

21. Monkhorst, H.J.; Pack, J.D. Special points for Brillouin-zone integrations. Phys. Rev. B 1976, 13, 5188. [CrossRef]

22. Blöchl, P.E. Projector augmented-wave method. Phys. Rev. B 1994, 50, 17953. [CrossRef] [PubMed]

23. Ravindran, P.; Fast, L.; Korzhavyi, P.A.; Johansson, B.; Wills, J.; Eriksson, O. Density functional theory for calculation of elastic properties of orthorhombic crystals: application to TiSi $i_{2}$. J. Appl. Phys. 1998, 84, 4891-4904. [CrossRef]

24. Reuss, A. Berechnung der fließgrenze von mischkristallen auf grund der plastizitätsbedingung für einkristalle. ZAMM-J. Appl. Math. Mech./Z. Für Angew. Math. Und Mech. 1929, 9, 49-58. [CrossRef]

25. Voigt, W. Lehrbuch der kristallphysik; Vieweg+Teubner Verlag: Wiesbaden, Germany, 1928; Volume 962.

26. Hill, R. The elastic behaviour of a crystalline aggregate. Proc. Phys. Soc. Sect. A 1952, 65, 349. [CrossRef]

27. Schneider, J.M.; Anders, A.; Hjörvarsson, B.; Petrov, I.; Macák, K.; Helmersson, U.; Sundgren, J.-E. Hydrogen uptake in alumina thin films synthesized from an aluminum plasma stream in an oxygen ambient. Appl. Phys. Lett. 1999, 74, 200-202. [CrossRef]

28. Greczynski, G.; Mráz, S.; Hultman, L.; Schneider, J. Venting temperature determines surface chemistry of magnetron sputtered TiN films. Appl. Phys. Lett. 2016, 108, 041603. [CrossRef]

29. Bolvardi, H.; Emmerlich, J.; Mraz, S.; Arndt, M.; Rudigier, H.; Schneider, J.M. Low temperature synthesis of Mo2BC thin films. Thin Solid Film. 2013, 542, 5-7. [CrossRef]

30. Walter, C.; Sigumonrong, D.; El-Raghy, T.; Schneider, J. Towards large area deposition of $\mathrm{Cr}_{2} \mathrm{AlC}_{\text {on steel. }}$ Thin Solid Film. 2006, 515, 389-393. [CrossRef] 
31. Paier, J.; Marsman, M.; Hummer, K.; Kresse, G.; Gerber, I.C.; Ángyán, J.G. Screened hybrid density functionals applied to solids. J. Chem. Phys. 2006, 124, 154709. [CrossRef]

32. Bai, Y.; Qi, X.; Duff, A.; Li, N.; Kong, F.; He, X.; Wang, R.; Lee, W.E. Density functional theory insights into ternary layered boride MoAlB. Acta Mater. 2017, 132, 69-81. [CrossRef]

33. Kota, S.; Agne, M.; Zapata-Solvas, E.; Dezellus, O.; Lopez, D.; Gardiola, B.; Radovic, M.; Barsoum, M.W. Elastic properties, thermal stability, and thermodynamic parameters of MoAlB. Phys. Rev. B 2017, 95, 144108. [CrossRef]

34. Ade, M.; Hillebrecht, $\mathrm{H}$. Ternary borides $\mathrm{Cr}_{2} \mathrm{AlB}_{2}, \mathrm{Cr}_{3} \mathrm{AlB}_{4}$, and $\mathrm{Cr}_{4} \mathrm{AlB}_{6}$ : the first members of the series $\left(\mathrm{CrB}_{2}\right) \mathrm{n} \mathrm{CrAl}$ with $\mathrm{n}=1,2,3$ and a unifying concept for ternary borides as MAB-phases. Inorg. Chem. 2015, 54, 6122-6135. [CrossRef] [PubMed]

35. Pugh, S. XCII. Relations between the elastic moduli and the plastic properties of polycrystalline pure metals. Philos. Mag. 1954, 45, 823-843. [CrossRef]

36. Pettifor, D. Theoretical predictions of structure and related properties of intermetallics. Mater. Sci. Tech. 1992, 8, 345-349. [CrossRef]

37. Bolvardi, H.; Emmerlich, J.; Baben, M.T.; Music, D.; von Appen, J.; Dronskowski, R.; Schneider, J.M. Systematic study on the electronic structure and mechanical properties of $\mathrm{X} 2 \mathrm{BC}(\mathrm{X}=\mathrm{Mo}, \mathrm{Ti}, \mathrm{V}, \mathrm{Zr}, \mathrm{Nb}, \mathrm{Hf}, \mathrm{Ta}$ and $\mathrm{W})$. J. Phys-Condens. Mat. 2013, 25. [CrossRef]

38. Wang, A.; Shang, S.; Du, Y.; Kong, Y.; Zhang, L.; Chen, L.; Zhao, D.; Liu, Z. Structural and elastic properties of cubic and hexagonal TiN and AIN from first-principles calculations. Comp. Mater. Sci. 2010, 48, 705-709. [CrossRef]

39. Gibson, J.S.-L.; Rezaei, S.; Rueß, H.; Hans, M.; Music, D.; Wulfinghoff, S.; Schneider, J.M.; Reese, S.; Korte-Kerzel, S. From quantum to continuum mechanics: studying the fracture toughness of transition metal nitrides and oxynitrides. Mater. Res. Lett. 2018, 6, 142-151. [CrossRef]

40. Tasnádi, F.; Odén, M.; Abrikosov, I.A. Ab initio elastic tensor of cubic Ti 0.5 Al $0.5 \mathrm{~N}$ alloys: dependence of elastic constants on size and shape of the supercell model and their convergence. Phys. Rev. B 2012, 85, 144112. [CrossRef]

(C) 2019 by the authors. Licensee MDPI, Basel, Switzerland. This article is an open access article distributed under the terms and conditions of the Creative Commons Attribution (CC BY) license (http://creativecommons.org/licenses/by/4.0/). 